\title{
Forward and Reverse Stock Splits: A Test of Market Efficiency
}

\author{
Frank W. Bacon \\ Longwood University \\ Kate M. Spradlin \\ Longwood University
}

\begin{abstract}
The purpose of this study is to utilize the risk adjusted event study methodology to test the magnitude and timing of any effect that a stock split announcement has on a firm's stock price. By analyzing market reactions of 50 NYSE or NASDAQ stock splits and comparing them to the corresponding dates' $S \& P 500$ performance, it is possible to determine if investors are able to earn above normal risk adjusted returns by acting on public announcements. The results suggest that investors would not be able to make atypical returns on the announcement of stock splits, supporting semi-strong form market efficiency.
\end{abstract}

Keywords: Market Efficiency, Stock Split Announcements

\section{INTRODUCTION}

Stock splits were once a very common financial practice firms used to manipulate their stock price. However, there has been a decline in the occurrence of stock splits in recent years; in 2017, only two S\&P 500 companies split their stock compared to 93 splits in 1997 (Eisen \& Holm, 2017). In the past, firms used stock splits to lower stock price, making it more affordable for individual investors to invest directly. But, due to the rise in popularity of alternative investment vehicles and an increase in average household income, it is no longer necessary to control for such low prices (Minnick \& Raman, 2014). Nevertheless, by studying the market's reaction to stock split announcements, it is possible to test market efficiency.

Firms can choose to conduct either a forward stock split or a reverse stock split. In the case of a forward split, the firm increases shares while proportionally decreasing stock price; a regular two-for-one stock split occurs when the number of shares is doubled, and the stock price is cut in half. For example, if an investor owned 100 shares of stock priced at \$200 per share, the split would double the number of shares to 200 at a price of $\$ 100$ each. A reverse split, one-for-two, operates in an opposite manner. Therefore, an investor holding 100 shares priced at $\$ 200$ per share would receive 50 shares priced at $\$ 400$ per share. Because the value of the investment in the firm remains the same, stock splits are merely a cosmetic change, but it is speculated that stock splits signal information about a firm's future cash flows (Mcnichols \& Dravid, 1990).

Investors speculate that it is possible to earn above average risk adjusted returns by trading according to the public announcement of a stock split. Forward splits are seen as a positive signal that the company is doing well and expects success in the future. However, reverse splits send a negative signal, 
accompanied by a decrease in stock price (Woolridge \& Chambers, 1983). In a semi-strong form efficient market that reacts to all public information, it should not be possible to earn above normal risk adjusted returns on this type of public announcement (Fama, 1970). This study aims to determine the type of efficiency displayed in the market by assessing the investor's ability to earn above average returns by reacting to stock split announcements.

\section{PROBLEM AND PURPOSE}

How will stock prices returns of firms that implement forward stock splits react to the split announcement? How will firms' stock prices returns react to a reverse stock split announcement? More specifically, how quickly does the market price react to one of these events?

The purpose of this study is to test market efficiency by studying how stocks' risk adjusted rates of return react to forward or reverse stock split announcements. Two samples of 25 firms, one representing firms that announced forward stock splits and one representing firms that with reverse stock splits, will be tested using the standard risk adjusted event study methodology from the finance literature. Market efficiency is tested by comparing risk adjusted rates of return of firms that perform forward stock splits to market returns, expecting a positive reaction. Similarly, risk adjusted rates of return for companies that implemented reverse stock splits will be compared to market returns, but, in this case, a negative reaction is expected. Ultimately, for both forward and reverse splits, market efficiency will be tested to see if the market exhibits weak, semi-strong, or strong form efficiency by examining the timing of the market's reaction to these events.

\section{LITERATURE REVIEW}

When performing a forward stock split, a firm increases the number of shares outstanding by replacing each outstanding share of stock with multiple shares, according to a specified formula; the increase in outstanding shares is also accompanied by a proportional decrease in price per share (Bacon \& Greis 2008). According to signaling theory, firms use forward stock splits to convey positive information about their future earnings, which is reflected positively in stock price (Huang, Liano, \& Pan, 2006; Grinblatt, Masulis, \& Titman, 1984). Forward stock splits serve as positive signals because investors trust that management is knowledgeable about investment decisions and that they use forward stocks splits to convey positive insider information about the firm. There is also a belief that management would not conduct a forward split unless they were confident it would generate positive returns (Ikenberry, Rankine, \& Stice, 1996). Alternatively, a reverse stock split involves decreasing the number of shares with an increase in stock price (Neuhauser \& Thompson, 2016). Reverse stock splits occur much less frequently than forward splits because investors perceive them negatively, so firms only conduct them when they feel it is imperative. According to He and Wang (2012), there are three theories regarding why firms conduct reverse stock splits. First, firms are trying to move their stock price or the tick size, minimum price movement divided by tick size, into an optimal range. Firms may also perform a stock split as a signal to investors because it is a way to convey inside information about the organization. The procedure/structure hypothesis suggests that firms perform stock splits to take advantage of the structural phenomenon of the market, such as positive return between the announcement and ex-split day. In either case, when firms announce stock splits, investors form predictions about the future success of the company. Consequently, stock price is affected because investors trade on the basis of this public information. According to signaling theory, the announcement of a stock split will cause a change in stock price, even though the split is a cosmetic change. By measuring the market's reaction to a stock split, it is possible to test for market efficiency.

Fama (1970) categorizes market efficiency into three forms: weak form efficient, semi-strong form efficient, and strong form efficient. Weak form efficiency states that it is impossible for investors to earn above average risk adjusted economic returns based on all historical information (Fama, 1970; Jensen 1978). Random walk theory is found to support weak form efficiency in numerous studies because it 
holds that historical trends are not useful in predicting future stock price movement (Fama, 1965; Levy, 1967, Fama \& Boume, 1966). If the market proves to be weak form efficient, it is then tested for semistrong form efficiency, which states investors should not be able to earn excess returns based on all public information (Fama, 1970; Bacon \& Greis, 2008; Jensen, 1978). For example, investors should not be able to earn excess returns on the public announcement of a stock split because the market will react too quickly and efficiently. Lastly, strong form efficiency suggests the market reacts to all relevant information, both public and private, so fast that no one can earn above normal risk adjusted returns by acting on this type of information (Fama, 1970). If this is true, it could reflect evidence that even illegal insider trading based on private information would not yield above normal risk adjusted returns. However, in reality, there is not much evidence to support strong form efficiency (Rozeff and Zaman, 1988).

At what level of efficiency does the market react to the public announcement of stock splits? In the case of a stock split announcement, weak form efficiency would only take past information into consideration, detracting from its relevance in this scenario. Likewise, strong form efficiency would include private information, which would not be available in a public announcement. Thus, this study focuses on semi-strong form efficiency and the ability of investors to gain an above normal risk adjusted return by reacting to public information. If the market reacts in a semi-strong form efficient manner, the stock prices should reflect all public information and eliminate the opportunity to capitalize on this information.

\section{METHODOLOGY}

This study will test for semi-strong form market efficiency using the standard risk adjusted event study methodology in the finance literature. Two samples of stocks will be analyzed, one representing firms that performed a forward stock split and one representing firms that performed a reverse stock split. The sample of firms that performed forward stock splits was randomly selected from firms that trade on the NYSE or NASDAQ and performed a 2 for 1 split between August 1, 2012 and June 1, 2018. The firms that performed reverse splits were randomly selected among firms traded on the NYSE or NASDAQ and performed a 1 for 5 split between February 1, 2015 and June 1, 2018. Table 1 and Table 2 describe the samples. 
TABLE 1

DESCRIPTION OF FORWARD STOCK SPLIT SAMPLE

\begin{tabular}{|l|l|l|c|}
\hline Firm & Ticker & Exchange & Announcement Date \\
\hline Windstream Holdings, Inc. & WIN & NASDAQ & $5 / 25 / 18$ \\
\hline Fibrocell Science, Inc. & FCSC & NASDAQ & $5 / 24 / 18$ \\
\hline Curis Inc. & CRIS & NASDAQ & $5 / 22 / 18$ \\
\hline Biolase Inc. & BIOL & NASDAQ & $5 / 10 / 18$ \\
\hline Staffing 360 Solutions Inc. & STAF & NASDAQ & $1 / 3 / 18$ \\
\hline CPI Card Group Inc. & PMTS & NASDAQ & $12 / 19 / 17$ \\
\hline Comstock Mining Inc. & LODE & NYSE & $10 / 31 / 17$ \\
\hline Astrotech Corp. & ASTC & NASDAQ & $10 / 13 / 17$ \\
\hline STRATA Skin Sciences Inc. & SSKN & NASDAQ & $10 / 6 / 17$ \\
\hline Soleno Therapeutics Inc. & SLNO & NASDAQ & $10 / 5 / 17$ \\
\hline Bridgeline Digital Inc. & BLIN & NASDAQ & $7 / 24 / 17$ \\
\hline Bellatrix Exploration Ltd. & BXE & NYSE & $5 / 17 / 17$ \\
\hline MannKind Corp. & MNKD & NASDAQ & $3 / 2 / 17$ \\
\hline ReneSola Ltd. & SOL & NYSE & $1 / 30 / 17$ \\
\hline Renren Inc. & RENN & NYSE & $1 / 6 / 17$ \\
\hline Cincinatti Bell Inc. & CBB & NYSE & $8 / 2 / 16$ \\
\hline Lightbridge Corp. & LTBR & NASDAQ & $7 / 5 / 16$ \\
\hline Resolute Energy Corp. & REN & NYSE & $5 / 27 / 16$ \\
\hline Seanergy Maritime Holdings Corp. & SHIP & NASDAQ & $1 / 7 / 16$ \\
\hline Frontline Ltd. & FRO & NYSE & $12 / 23 / 15$ \\
\hline Acura Pharmaceuticals & ACUR & NASDAQ & $8 / 24 / 15$ \\
\hline Chimera Investment Corp. & CIM & NYSE & $3 / 17 / 15$ \\
\hline Assembly Biosciences Inc. & ASMB & NASDAQ & $7 / 14 / 14$ \\
\hline Seacoast Banking Corporation of Florida & SBCF & NASDAQ & $11 / 27 / 13$ \\
\hline iCAD Inc. & ICAD & NASDAQ & $8 / 14 / 12$ \\
\hline & & & \\
\hline
\end{tabular}


TABLE 2

DESCRIPTION OF REVERSE STOCK SPLIT SAMPLE

\begin{tabular}{|l|l|l|c|}
\hline Firm & Ticker & Exchange & Announcement Date \\
\hline Exponent Inc. & EXPO & NASDAQ & $5 / 31 / 18$ \\
\hline Jewett-Cameron Trading Company Ltd. & JCTCF & NASDAQ & $5 / 9 / 18$ \\
\hline Brown \& Brown Inc. & BRO & NYSE & $2 / 26 / 18$ \\
\hline Fiserv Inc. & FISV & NASDAQ & $2 / 22 / 18$ \\
\hline AFLAC Inc. & AFL & NYSE & $2 / 13 / 18$ \\
\hline Cognex Corp. & CGNX & NASDAQ & $11 / 14 / 17$ \\
\hline Henry Schein Inc. & HSIC & NASDAQ & $8 / 16 / 17$ \\
\hline Ball Corp. & BLL & NYSE & $4 / 26 / 17$ \\
\hline Copart Inc. & CPRT & NASDAQ & $3 / 24 / 17$ \\
\hline Comcast Corp. & CMCSA & NASDAQ & $1 / 26 / 17$ \\
\hline USANA Health Sciences & USNA & NYSE & $10 / 25 / 16$ \\
\hline A. O. Smith Corp. & AOS & NYSE & $9 / 7 / 16$ \\
\hline The Toro Co. & TTC & NYSE & $8 / 18 / 16$ \\
\hline Badger Meter Inc. & BMI & NYSE & $8 / 12 / 16$ \\
\hline Church \& Dwight Co. Inc. & CHD & NYSE & $8 / 4 / 16$ \\
\hline Alliant Energy Corp. & LNT & NYSE & $4 / 20 / 16$ \\
\hline Hormel Foods C. & HRL & NYSE & $11 / 25 / 15$ \\
\hline Edward Lifesciences Corp. & EW & NYSE & $11 / 19 / 15$ \\
\hline Nike Inc. & NKE & NYSE & $11 / 19 / 15$ \\
\hline Global Payments Inc. & GPN & NYSE & $10 / 7 / 15$ \\
\hline The Kroger Co. & KR & NYSE & $6 / 25 / 15$ \\
\hline IDEXX Laboratories Inc. & IDXX & NASDAQ & $5 / 6 / 15$ \\
\hline Marathon Petroleum Corp. & MPC & NYSE & $4 / 29 / 15$ \\
\hline Starbucks Corp. & SBUX & NASDAQ & $3 / 18 / 15$ \\
\hline Magna International Inc. & MGA & NYSE & $2 / 25 / 15$ \\
\hline
\end{tabular}

In order to test for semi-strong form market efficiency in response to stock splits, stock returns around the forward or reverse stock split announcements were analyzed. The study presents the following hypotheses:

\section{Forward Stock Splits}

H10: The risk adjusted rate of return of the stock price of the sample firms is not significantly positively affected by the forward stock split on the announcement date.

$\mathrm{H1}_{1}$ : The risk adjusted rate of return of the stock price of the sample firms is significantly positively affected by the forward stock split on the announcement date.

H2 $2_{0}$ : The risk adjusted rate of return of the stock price of the sample firms is not significantly positively affected by the forward stock split around the announcement date as defined by the event period.

$\mathrm{H}_{1}$ : The risk adjusted rate of return of the stock price of the sample firms is significantly positively affected by the forward stock split around the announcement date as defined by the event period. 


\section{Reverse Stock Splits}

H1: : The risk adjusted rate of return of the stock price of the sample firms is not significantly negatively affected by the reverse stock split on the announcement date.

$\mathrm{H1}_{1}$ : The risk adjusted rate of return of the stock price of the sample firms is significantly negatively affected by the reverse stock split on the announcement date.

$\mathrm{H}_{0}$ : The risk adjusted rate of return of the stock price of the sample firms is not significantly negatively affected by the reverse stock split around the announcement date as defined by the event period.

$\mathrm{H}_{1}$ : The risk adjusted rate of return of the stock price of the sample firms is significantly negatively affected by the reverse stock split around the announcement date as defined by the event period.

For this study, all of the stock return information for both samples were collected from Yahoo! Finance; historical data, such as the return of the S\&P 500 over the event period, were also collected from Yahoo! Finance. The date of the stock split announcement represents day 0 in the analysis. The final analysis was conducted by:

1. Obtaining the historical stock prices of the samples of firms and S\&P 500 Index for the event study duration of -180 days to +30 days. The event period is defined as day -30 to +30 , with day 0 being the date of the stock split announcement.

2. Holding period returns of the $S \& P 500$ Index $\left(R_{M}\right)$, and the sample firms $(R)$ will be calculated for each day of the study using the following formula:

Current Daily Return $=($ current day close price- previous day close price $)$

previous day close price

3. Using the holding period returns, a regression analysis was performed for each sample with the actual daily return for each company as the dependent variable and regressing it on the corresponding S\&P 500 Index, the independent variable. The regression was performed over the pre-event period (day -180 to -30 ) to obtain the intercept, alpha, and the standardized coefficient, beta, for each firm. Table 3 below shows alphas and betas for each firm. 
TABLE 3

ALPHAS AND BETAS OF STUDY SAMPLES

\begin{tabular}{|l|c|c|l|c|c|}
\hline \multicolumn{3}{|c|}{ Forward Spits } & \multicolumn{3}{c|}{ Reverse Splits } \\
\hline Ticker & Alpha & Beta & Ticker & Alpha & Beta \\
\hline EXPO & 0.000895 & 0.710371 & WIN & -0.002108 & 1.678419 \\
\hline JCTCF & 0.001045 & -0.352229 & FCSC & -0.008234 & 0.884582 \\
\hline BRO & 0.001033 & 0.398919 & CRIS & -0.008306 & 1.442558 \\
\hline FISV & -0.000340 & 1.055428 & BIOL & -0.000620 & -0.036467 \\
\hline AFL & 0.000739 & 0.648594 & STAF & -0.000687 & -0.012538 \\
\hline CGNX & 0.001704 & 2.182316 & PMTS & -0.006617 & -0.578221 \\
\hline HSIC & 0.000635 & 1.008109 & LODE & -0.002283 & 0.310858 \\
\hline BLL & -0.000913 & 1.029941 & ASTC & -0.004282 & 0.494834 \\
\hline CPRT & 0.000485 & -0.920011 & SSKN & -0.002826 & 0.045275 \\
\hline CMCSA & 0.000453 & 0.720421 & SLNO & -0.005953 & 0.929507 \\
\hline USNA & -0.000242 & 1.250791 & BLIN & -0.001943 & 3.384161 \\
\hline AOS & 0.000625 & 1.316351 & BXE & -0.000725 & 2.191466 \\
\hline TTC & 0.001138 & 0.988807 & MNKD & -0.002068 & 1.613692 \\
\hline BMI & 0.001303 & 0.850098 & SOL & -0.004343 & 0.926085 \\
\hline CHD & 0.001267 & 0.599716 & RENN & -0.003363 & 1.278427 \\
\hline LNT & 0.001285 & 0.501642 & CBB & 0.001383 & 1.204627 \\
\hline HRL & 0.001419 & 0.783398 & LTBR & -0.003743 & 0.869287 \\
\hline EW & 0.000926 & 1.046319 & REN & 0.002431 & 2.144874 \\
\hline NKE & 0.001889 & 0.967702 & SHIP & 0.001094 & 1.191033 \\
\hline GPN & 0.001850 & 1.106007 & FRO & 0.003186 & 1.453007 \\
\hline KR & 0.001838 & 0.605307 & ACUR & 0.006644 & 0.294954 \\
\hline IDXX & 0.001059 & 0.715539 & CIM & -0.000017 & 0.245923 \\
\hline MPC & 0.000533 & 1.187400 & ASMB & -0.003417 & 1.189579 \\
\hline SBUX & 0.000811 & 0.721230 & SBCF & -0.001118 & 1.606406 \\
\hline MGA & -0.000228 & 1.258467 & ICAD & -0.001365 & -0.034532 \\
\hline
\end{tabular}

4. To calculate the normal expected returns, the risk-adjusted method (market model) was used. The expected returns for each stock, for each day of the event period was calculated using the formula:

$\mathrm{E}(\mathrm{R})=\mathrm{alpha}+\operatorname{Beta}\left(\mathrm{R}_{\mathrm{m}}\right)$

5. Then, the excess return was calculated as:

$\mathrm{ER}=$ actual return $-\mathrm{E}(\mathrm{R})$

6. Average Excess Returns was found for each day by averaging the Excess Returns for each firm on a given day.

$\mathrm{AER}=$ Sum of Excess Returns $/ \mathrm{n}$ $\mathrm{n}=$ number of sample firms 
7. In addition, cumulative AER was calculated by adding the AERs for each day of the event period, days -30 to +30 .

8. For the event period, graphs of AER and CAER were plotted to show their movement over time. Charts 1 and 2 below display the Average Excess Returns plotted against time. Charts 3 and 4 depict the Cumulative Average Excess Returns plotted against time.

\section{QUANTITATIVE TESTS AND RESULTS}

Did the market actually react to the information regarding the reverse and forward stock splits? Was the information surrounding the event significant? If the information surrounding the event was significant and contributed to a change in stock price in either direction, negative or positive, there would be a substantial difference between the Actual Average Daily Returns (Day -30 to Day +30) and the Expected Average Daily Returns (Day -30 to +30 ). In order to test for a significant difference between the Actual Average Daily Returns and the Expected Average Daily Returns for both samples of stock splits, a paired sample t-test was conducted. For the sample of two-for-one forward stick splits, the paired sample t-test provided evidence at the $10 \%$ significance level that there was a difference between the Actual Average Daily Returns and the risk-adjusted Average Expected Daily Returns. These results support the hypothesis for forward stock splits $\mathrm{H} 2_{1:}$ the risk adjusted rate of return of the stock price of the sample firms is significantly positively affected by the forward stock split around the announcement date as defined by the event period. Similarly, when the paired sample t-test was conducted for the sample of one-for-five reverse stock splits, there was evidence at the $5 \%$ significance level that there was a difference between the Actual Average Daily Returns and the Average Expected Daily Returns. For the sample of reverse splits, the evidence also supports hypothesis $\mathrm{H} 2_{1}$ : The risk adjusted rate of return of the stock price of the sample firms is significantly negatively affected by the reverse stock split around the announcement date as defined by the event period. Because a market reaction was observed and there was significant evidence that the information surrounding the event date for both types of stock splits impacted stock price, there is support that the market did react to the announcements of the stock splits.

In addition, it is important to test the stock price reaction to the stock split announcement to determine the level of efficiency of the market response. Basically, did the market display weak, semi-strong, or strong form market efficiency? By analyzing the market reaction, it is possible to conclude how quickly the market reacted to the announcement of either a forward or reverse stock split.

The main factor in examining market efficiency is testing to see if the Average Excess Return (AER) and the Cumulative Average Excess Return (CAER) for both samples of stock splits are significantly different than zero; the other factor is observing a graphical relationship between time and AER or CAER (Charts 1, 2 3, and 4). T-tests of both AER and CAER for the sample of forward stock splits both indicated that the means were different than zero at the $10 \%$ significance level. Likewise, $t$-tests of both the AER and CAER for the sample of reverse stock splits also showed that the means were different from zero at the 10\% significance level. Observation of Chart 3 (Forward Stock Split CAER) highlights the significant positive reaction of the risk adjusted returns of the sample stocks up to 28 days before the stock split announcement was made. Also, the evaluation of Chart 4 (Reverse Stock Split CAER) shows the market's reaction with the change of the risk adjusted returns being negatively impacted up to 27 days before the announcement date. 
FIGURE 1

FORWARD STOCK SPLITS: AVERAGE EXCESS RETURNS OVER EVENT PERIOD

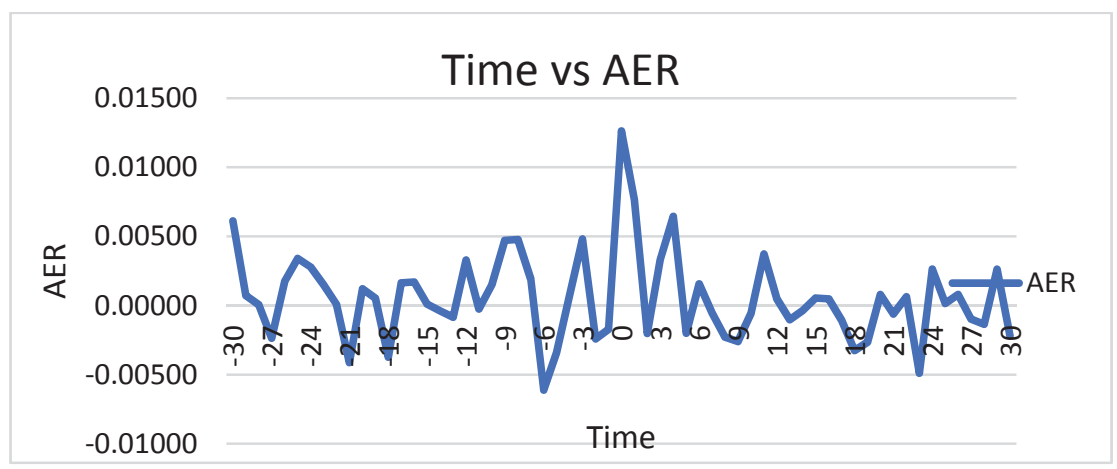

FIGURE 2

REVERSE STOCK SPLITS: AVERAGE EXCESS RETURNS OVER EVENT PERIOD

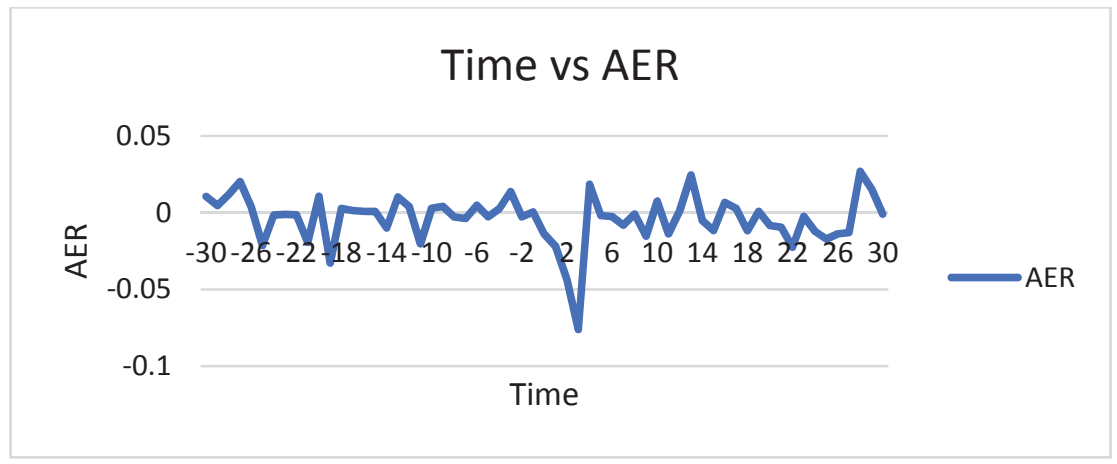

FIGURE 3

FORWARD STOCK SPLITS: CUMULATIVE AVERAGE EXCESS RETURNS OVER EVENT PERIOD

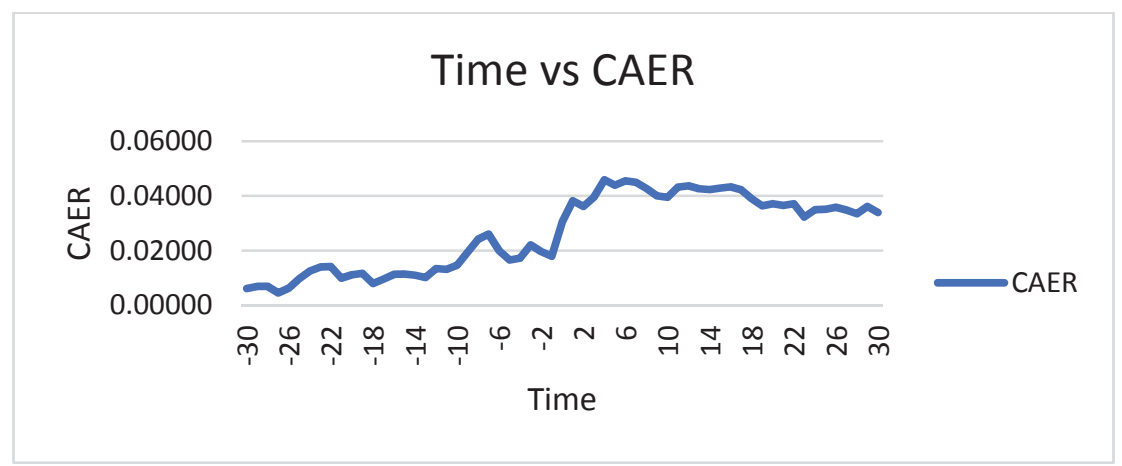




\section{FIGURE 4 \\ REVERSE STOCK SPLITS: CUMULATIVE AVERAGE EXCESS RETURNS OVER EVENT PERIOD}

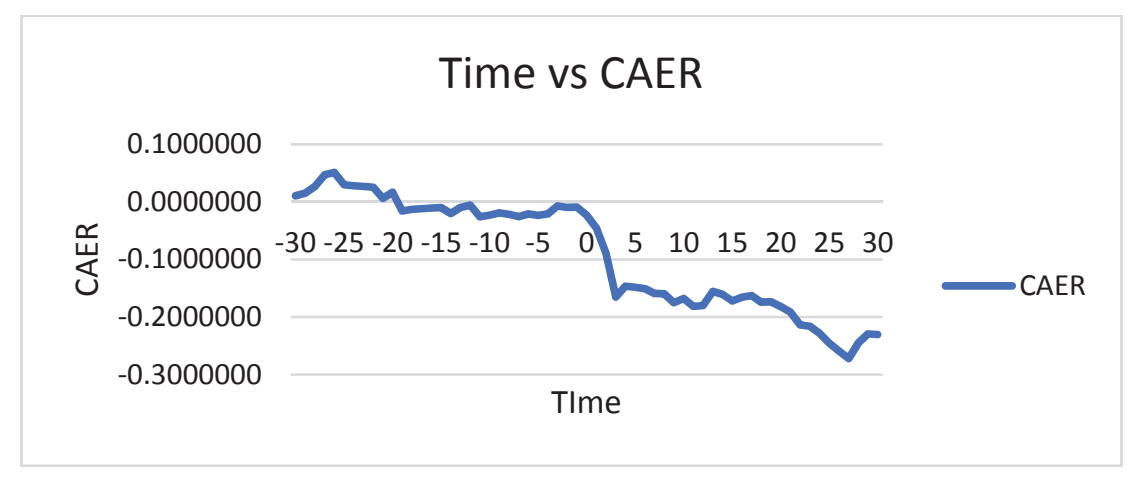

Chart 3 shows that the announcements of stock splits significantly positively affected the firm's stock price up to 28 days before day 0 , the announcement date for a two-for-one stock split. This supports the null hypothesis for forward stock splits $\mathrm{H}_{1}$ : The risk adjusted rate of return of the stock price of the sample firms is not significantly positively affected by the forward stock split on the announcement date. Consequently, an investor would not be able to make an above normal return if they were to act on the announcement of a two-for-one stock split. Before the announcement date, the stock price had already adjusted to the news of the stock split announcement. For reverse splits, the market also reacts to the announcement of the split before the event happens. In this case, the stock prices begin to be affected up to 27 days before the announcement date, day 0 . This supports the hypothesis for reverse stock splits $\mathrm{H}_{0}$ : The risk adjusted rate of return of the stock price of the sample firms is not significantly negatively affected by the reverse stock split on the announcement date. In a similar manner to a forward split, an investor would not be able to make an above normal return by selling their stock on the announcement date because the stock price would have already adjusted. In both cases, semi-strong form market efficiency is supported, meaning the market reflects all publicly available information.

In addition, in both CAER graphs, there is slight movement in the opposite direction of the prevailing trend after the event date. For the forward stock splits, this happens at day 6 when the CAER drops slightly, and for the reverse splits, this happens at day 3 when the CAER rises slightly. Consistent with the behavioral finance literature, these movements suggest that the market overreacted to the stock split announcement and the market is adjusting. Consequently, this information bolsters the evidence that the market is semi-strong form efficient and reacts to all public information.

\section{CONCLUSION}

The purpose of this study was to test market efficiency theory by analyzing the effects of both forward and reverse stock splits on a sample 50 NYSE or NASDAQ traded firms that announced stock splits (25 forward splits and 25 reverse splits). By gathering data surrounding the stock splits announcement of each firm and comparing it to the corresponding S\&P 500 performance, it is possible to determine the timing and degree of influence that a firm's stock split announcement has on its stock price risk adjusted return. Using the standard risk adjusted event study methodology, it is apparent that investors are unable to gain an above average return by reacting to a forward or reverse stock split announcement. Evidence shows, in both CAER graphs, that stock prices do not react in a manner that would allow for an investor to gain abnormal returns by acting on the announcements. Consistent with the behavioral finance literature, the study reveals stock price movement in the opposite direction of the expected trend several days after the event date, which shows a correction to a market overreaction to the announcement. Likewise, the evidence shows significant stock price return reaction up for forward and 
down for reverse stock splits up to 28 days prior to the announcement consistent with the existence of insider trading. This insight further supports evidence for semi-strong form market efficiency because the market reacts to all public information.

Specifically, for this study, forward stock splits are considered good news for investors, while reverse stock splits are typically viewed as negative signals. Forward splits are viewed by investors as indicators of growth and ensuing higher stock prices. Conversely, reverse splits are a seen as a forewarning for negative returns, and they are used mostly by firms who are in need of fundamental changes. Stock price reacts differently based on the nature of the stock split, but regardless of the direction of the price change, semi-strong form market efficiency does not allow investors to act on the announcement of stock splits to earn abnormal returns.

\section{REFERENCES}

Bacon, F.W., \& J. Greis. (2008). Stock Split Announcements: A Test of Market Efficiency. Journal of Business and Behavioral Sciences, 18(1), 18-27.

Eisen, B., \& Holm, E. (2017). Amazon's Brush with \$1,000 Signals the Death of the Stock Split. Fox Business. Web.

Fama, E. F. (1965). The Behavior of Stock Market Prices. The Journal of Business, 38(1), 34-105.

Fama, E. F. (1970). Efficient Capital Markets: A Review of Theory and Empirical Work. The Journal of Finance, 25(2), 383-417.

Fama, E. F., \& Blume, M. E. (1966). Filter Rules and Stock-Market Trading. The Journal of Business, 39(1), 226-241.

Grinblatt, M., Masulis, R. W., \& Titman, S. (1984). The Valuation Effects of Stock Splits and Stock Dividends. Journal of Financial Economics, 13(4).

He, Y., \& Wang, J. (2012). Stock Split Decisions: A Synthesis of Theory and Evidence. Journal of Applied Finance, 22(2) 124-142.

Huang, G., Liano, K., \& Pan, M. (2006). Do Stock Splits Signal Future Profitability?. Review of Quantitative Finance and Accounting, 26(4), 347-367.

Ikenberry, D., Rankine, G., \& Stice, E. (1996). What Do Stock Splits Really Signal? The Journal of Financial and Quantitative Analysis, 31(3), 357-375.

Jensen, M. C. (1978). Some Analogous Evidence Regarding Market Efficiency. Journal of Financial Economics, 6(2/3), 95-101.

Levy, R. A. (1967). The Theory of Random Walks: A survey of Findings. American Economist, 11(2), 34-48.

Mcnichols, M., \& Dravid, A. (1990). Stock Dividends, Stock Splits, and Signaling. The Journal of Finance, 45(3), 857-879.

Minnick, K., \& Raman, K. (2014). Why are Stock Splits Declining?. Financial Management, 43(1), 2960.

Neuhauser, K.L., \& Thompson, T. H. (2016). Survivability Following Reverse Stock Splits: What Determines the Fate of Non-Surviving Firms?. Journal of Economics and Business, 83(1), 1-22.

Rozeff, M. S., \& Zaman, Z. A. (1988). Market Efficiency and Insider Trading: New Evidence. The Journal of Business, 61(1), 25-44.

Woolridge, J. R., \& Chambers, D. R. (1983). Reverse Splits and Shareholder Wealth. Financial Management, 12(3), 5-15. 